\title{
Langmuir and Langmuir-Blodgett films of capsules of haemoglobin at air/water and solid/air interfaces
}

\author{
J MAHESHKUMAR and A DHATHATHREYAN* \\ Chemical Lab., CSIR-Central Leather Research Institute, Adyar, Chennai 600 020, India \\ e-mail: aruna@clri.res.in
}

MS received 16 April 2012; accepted 10 October 2012

\begin{abstract}
Organized assemblies of capsules of haemoglobin (Hb), in the size range of 0.1 to $0.3 \mu$ in Langmuir films have been studied at air/water interface below and above the isoelectric point. Spread films of these organizates suggest that there is no expulsion of individual particles or particle assemblies at the interface and the particles are stable. Dynamic surface tension and the associated dilational and shear visco-elasticity in these films suggest that the capsules are highly elastic. Multilayer films of the capsules using Langmuir-Blodgett technique have been fabricated by sequential deposition on solid surfaces. These films have been characterized by circular dichroism spectroscopy (CD), atomic force microscopy (AFM), quartz crystal microbalance (QCM) and Fourier transform infrared with reflection absorption spectroscopy (FTIR-RAS). No appreciable change in the secondary structural features of $\mathrm{Hb}$ is seen from CD studies indicating the stability of the protein in these organized assemblies. Sizes of these capsules change near the isoelectric point and large swollen multiwalled capsules are formed. The elastic films of capsules of $\mathrm{Hb}$ provide a useful post preparation approach for modification of the surface roughness, porosity, and permeability of pre-assembled polypeptide microcapsules.
\end{abstract}

Keywords. Haemoglobin; capsules; Langmuir-Blodgett films; pH; multi-walled capsules; isoelectric point.

\section{Introduction}

Drug delivery and storage of formulations in pharmaceutical applications require microencapsulation techniques. Many different methods have been used to develop encapsulation techniques for the purpose of controlled release and drug delivery. ${ }^{1}$ Among the different systems, colloidosomes and polyelectrolyte capsules $^{2-7}$ have attracted much attention. Recently, novel methods to design capsules of proteins have been reported and have been used to prepare nanomaterials. ${ }^{8,9}$ Biogenic capsules using Lipid/protein combinations developed recently are driven largely by the amphiphilic nature of the constituents in a manner similar to the shell materials and have shown excellent material stability and properties. ${ }^{10} \mathrm{Li}$ et al. have used alternating layers of human serum albumin (HSA) and L- $\alpha$ dimyristoyl phosphatidic acid to form biocapsules whose permeability can be controlled by $\mathrm{pH} .{ }^{11}$

Cavitation methods, complex coacervation and interfacial polymerization are some of the well-established techniques which have been used to prepare capsules of macromolecules. ${ }^{12-15}$ In order to encapsulate and use these either in biomaterials as slow and sustained release vehicles or as delivery systems, it is imperative

*For correspondence to find methods to form stable coating of the capsules on solid surfaces.

With this objective in focus, in this work, capsules of haemoglobin $(\mathrm{Hb})$ at $\mathrm{pH}=5.5$ and 7.5 below and above its isoelectric point ( $\mathrm{pI}=6.8$ ) were designed. The morphology and sizes of these capsules were characterized using confocal laser scanning microscope (CLSM). Organized assemblies of these capsules at the air/water interface in the form of spread films were formed and analysed as a function of initial bulk protein concentration and $\mathrm{pH}$. The elasticity and stability of these capsules were studied using dilational rheology of the protein films spread in a Langmuir trough. In order to understand the feasibility of preparing surfaces with well-ordered designed capsules for applications in biosensing devices, these films transferred to solid substrates were characterized using circular dichroism (CD) spectroscopy, atomic force microscopy (AFM), FTIR-RAS and QCM.

\section{Materials and methods}

\subsection{Capsule preparation}

Capsules of $\mathrm{Hb}$ at $\mathrm{pH} 5.5$ and 7.5 were prepared by dissolving $\mathrm{Hb}$ in the respective phosphate buffer 
(concentration $1 \mu \mathrm{M}$ ) and fast frozen in liquid nitrogen $\left(-196^{\circ} \mathrm{C}\right)$ which was incubated initially at $-20^{\circ} \mathrm{C}$ for $2 \mathrm{~h}$ (annealing step) after which it was slowly brought to $5^{\circ} \mathrm{C}$ and then crosslinked with $0.1 \%$ gluteraldehyde before lyophilization. Such a freezing-annealinglyophilization procedure resulted in globular structures ranging from $200 \mathrm{~nm}$ to about $10 \mu \mathrm{m}$. Particle size analysis of the capsules carried out using dynamic light scattering (Malvern zetasizer, model 3000 HSA) showed a major population (69\%) with an average size of about $0.1-0.2 \mu$ and populations of 1 to $2 \mu$ (18\%) and the rest in the range $3-4 \mu$.

The samples thus formed were analysed using Confocal laser scanning microscopy (CLSM) using the auto-fluorescence of the protein using a Leica (Germany) SP2-RS CLSM (scan speed 7.4 frames/s) microscope equipped with $488 \mathrm{~nm}$ Ar ion laser.

All the images were captured using a 100X/1.3NA oil-immersion objective lens and $100 \mathrm{~mm}$ pinhole and the images are averaged over 25 frames.

\subsection{Interfacial and dilational properties of $\mathrm{Hb}$ at air/water interface}

2.2a The Langmuir film balance (trough): Langmuir films of the capsules were prepared using a Nima Technology (England), Model $601 \mathrm{M}$ Langmuir trough with a miniature analytical film balance constructed from Teflon. All measurements were carried out at $\mathrm{T}=24^{\circ} \mathrm{C}$. The spread films of the capsules were stabilized at the interface by spreading them on buffer of $\mathrm{pH}=6.8$ (pI of the protein). This method of stabilizing different protein films by spreading them on buffers at the isoelectric point has been used by Dhathathreyan and co-workers. ${ }^{16-18}$ The average surface area versus surface pressure isotherms were recorded for these spread films. Surface pressure was measured using filter paper as Wilhelmy plate.

2.2b Dilational rheology of capsules at air/water interface: In another experiment the dilational rheology of the capsules of the protein spread in a Langmuir trough were studied using oscillatory compressions of the film with the Langmuir trough barriers and measuring the surface pressure and the phase shift between the surface tension signal and the surface area. By carrying out such uniaxial compressions the film is actually subject to both compression and shear. The effect of shear modulus can be overlooked, assuming that it is negligible compared to the compression modulus. Following a method developed by Cicuta and Terentjev ${ }^{19}$ spread monolayers of $\mathrm{Hb}$ (from very low dilutions) in a Langmuir trough were compressed using two symmetrical barriers and using 2 Wilhelmy balance positioned at midway, the films were compressed at about $5 \mathrm{~cm}^{2} / \mathrm{min}$. The surface pressure was recorded as function of time, while the area was changed by imposed oscillatory barrier movements. The surface pressure was measured with the two Wilhelmy plates at orthogonal orientations. In every experiment, the films were subjected to 20 oscillations cycle then aged for about 1 to $2 \mathrm{~h}$. Accuracy in elasticity and viscosity values are $\pm 1 \mathrm{mN} / \mathrm{m}$ and $\pm 1 \mathrm{mNs} / \mathrm{m}$. Each value reported here is the average of at least three trails.

2.2c Langmuir-Blodgett film technique: Multilayer films of these capsules were fabricated by sequential deposition on solid surfaces using LangmuirBlodgett film technique and changes in their sizes and structure on $\mathrm{pH}$ shift have been studied by circular dichroism (CD) spectroscopy, atomic force microscopy, quartz crystal microbalance (QCM) and Fourier transform infrared-attenuated total reflection spectroscopy (FTIR-RAS). The surface pressure was maintained constant at $\pi=20 \mathrm{mN} / \mathrm{m}$ and the change in surface area during dipping was monitored. A horizontal transfer method was used to prepare the films. The transfer ratio was around 0.75 for all the films.

The LB films of the capsules were transferred to Formvar/carbon coated copper grids (Mesh size 200) by horizontal transfer method. For the TEM studies these grids were analysed in a TECNAI FE12 TEM instrument operating at $120 \mathrm{kV}$ using SIS imaging software.

\subsection{Circular dichroic spectroscopy}

Circular dichroism measurements were performed on the samples using a spectropolarimeter, model J710 (Jasco, Japan), equipped with a Neslab RTE110 temperature controller (Neslab Instruments, USA) and calibrated with a standard solution of $(+)-10$ camphorsulphonic acid. The films of $\mathrm{Hb}$ capsules transferred at a surface pressure of $25 \mathrm{mN} / \mathrm{m}$ on quartz slides (Erma, FRG) were used in the far-UV (190-240 nm). Photomultiplier absorbance does not exceed $600 \mathrm{~V}$ in the spectral regions measured. Each spectrum has been signal-averaged at least five times, smoothed with Spectropolarimeter System Software, version 1.00 (Jasco), and baseline-corrected by subtracting the buffer spectrum. All the measurements were performed at $30^{\circ} \mathrm{C}$ under a nitrogen flow $(3 \mathrm{~L} / \mathrm{h})$. The secondary structural features were fitted using Dichroweb. ${ }^{20}$

The measured ellipticity values recorded in mdeg could not be normalized for path length or Capsule concentration. This does not change the ability of the 
technique to determine the structure of the protein, because as such information depends only on the shape of spectrum, not its magnitude at any given wavelength.

\subsection{Fourier transform infrared reflection-absorption spectroscopy (FTIR-RAS) measurements}

FTIR-RAS spectra were recorded using a Nicolet 710 spectrometer equipped with a MCT detector. The FTIRRAS spectrum of a bare gold plate was used as the reference. The films of $\mathrm{Hb}$ capsules were prepared by depositing an aliquot of the capsule containing solution onto a gold substrate and allowing it to dry overnight. All spectra were collected at a spectral resolution of $4 \mathrm{~cm}^{-1}$.

\subsection{QCM measurements}

Cleaned quartz substrates for QCM were stored in desiccator. Before use, they were re-exposed to UV/ozone for $10 \mathrm{~min}$. Measurements were performed in exchange mode, i.e., a volume of $50 \mu$ of temperature-stabilized and degassed sample liquid was delivered to the chamber containing the sensor crystal to ensure a complete exchange of the liquid. In this way, processes of adsorption and surface adlayer changes can be followed in situ while subsequently exposing different solutions to the surface. All measurements were performed at a temperature of $24-25^{\circ} \mathrm{C}$.

QCM sensors quartz crystal microbalance, crystal holders, and polished gold AT cut $5 \mathrm{MHz}$ gold crystals of $25 \mathrm{~mm}$ diameter crystals from Maxtek were used for the study. The oscillation frequency was measured using a Maxtek RQCM with phase lock oscillator and three independent crystal measurement channels. Data acquisition was performed using the Maxtek RQCM Data Logging software (v. 1.6.0) on a Pentium 4 PC connected through an RS232 serial interface. A sampling rate of $1 / 60 \mathrm{~Hz}$ was employed for all experiments. Any baseline drift was regulated using the coarse and fine capacitance adjustments. Upon interaction of (soft) matter with the surface of a sensor crystal, changes in the resonance frequency, $\Delta \mathrm{f}$ is related to attached mass (including coupled water), which is governed by the Sauerbray's equation.

$$
\Delta \mathrm{m}=-(\mu \rho)^{1 / 2}(\Delta \mathrm{f}) /\left(2 \mathrm{f}_{0}^{2}\right),
$$

$\mathrm{f}_{0}$ is the resonance frequency of the crystal $(5 \mathrm{MHz}$ at $\left.25^{\circ} \mathrm{C}\right), \mu$ is the shear modulus of the quartz crystal (2.947 X10 $11 \mathrm{~g} \mathrm{~s}^{-2} \mathrm{~cm}^{-1}$ at room temperature), and $\rho$ is the density of quartz $\left(2.648 \mathrm{gcm}^{-3}\right)$.

\section{Results and discussion}

A micro-phase separation between the bulk of the water (ice crystals) and protein/buffer compartment ${ }^{21}$ is expected to occur on fast-freezing of the protein dissolved in buffer using liquid $\mathrm{N}_{2}$. When the temperature of the frozen sample was increased to $-20^{\circ} \mathrm{C}$ and kept at that temperature for sometime, diffusion of protein molecules as a whole occurs and the protein molecules assemble into spheres. This is because the spherical structures are energetically more favoured than extended structures. The capsules formed at $\mathrm{pH}$ below and above the pI were stable for about a week while those formed at the pI showed aggregation and precipitation within 3 days.

(a)

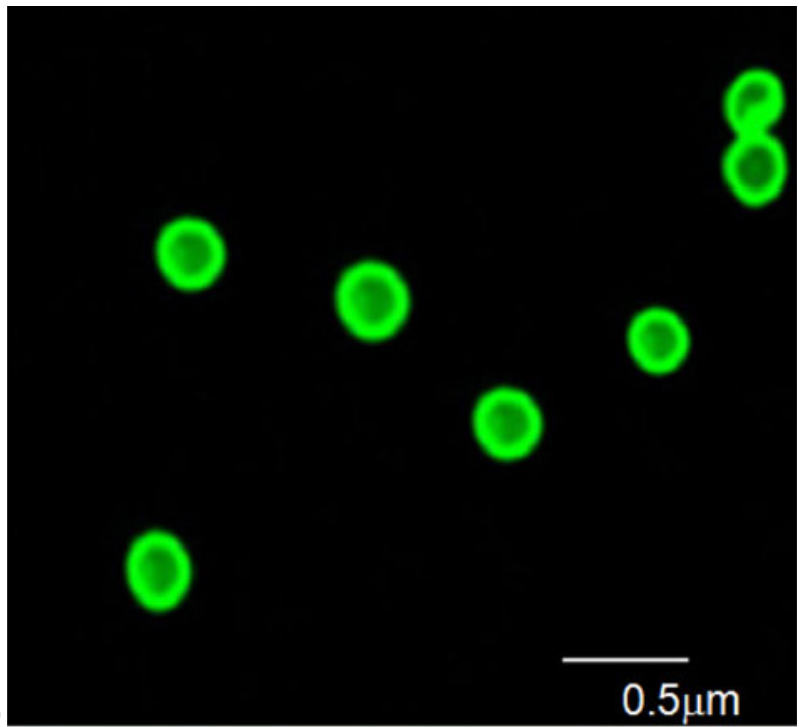

(b)

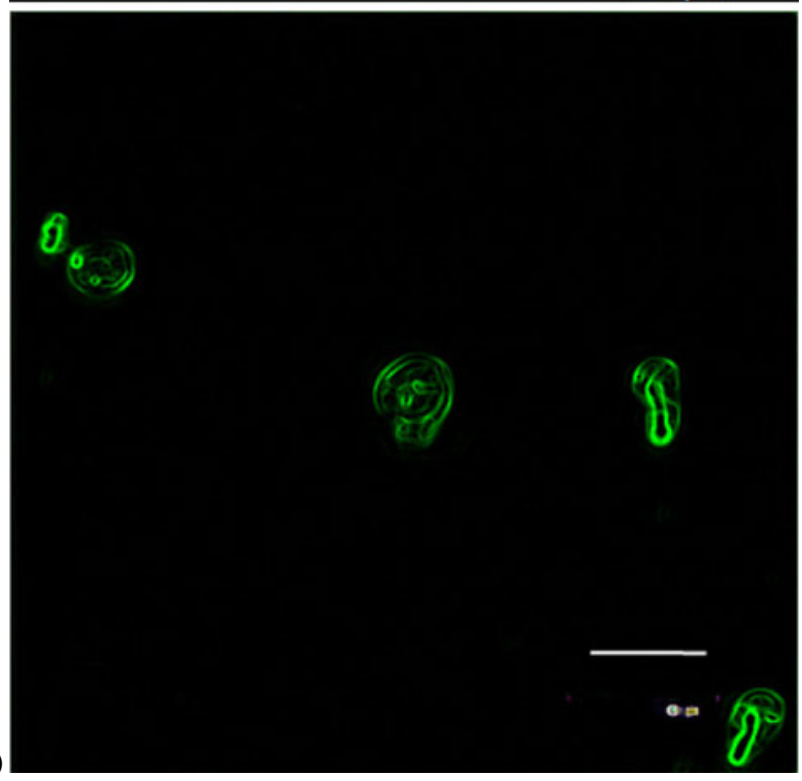

Figure 1. CLSM images of haemoglobin capsules at (a) $\mathrm{pH}=5.5$ and (b) $\mathrm{pH}=7.5$. 
Figure 1a and $\mathrm{b}$ show the CLSM fluorescent images of the $\mathrm{Hb}$ capsules at $\mathrm{pH}=5.5$ and 7.5. At $\mathrm{pH}=5.5$, the walls of the capsules are smooth and the protein seems to be distributed equally over the wall while the capsules themselves do not appear completely permeable. The width of the wall is about $50-80 \mathrm{~nm}$, depending on the size of the capsule. The results show that the fluorescence intensity of the interior and exterior of capsules is almost identical at $\mathrm{pH}=5.5$ while at $\mathrm{pH} 7.5$ the capsules interior become dark. This suggests that at the low $\mathrm{pH}$ most of macromolecules can penetrate into capsules.

This is similar to the properties of capsules reported by Duan et al. ${ }^{22}$ As $\mathrm{pH}$ of the capsules is increased to 7.5 , the capsules aggregate and capsules of different
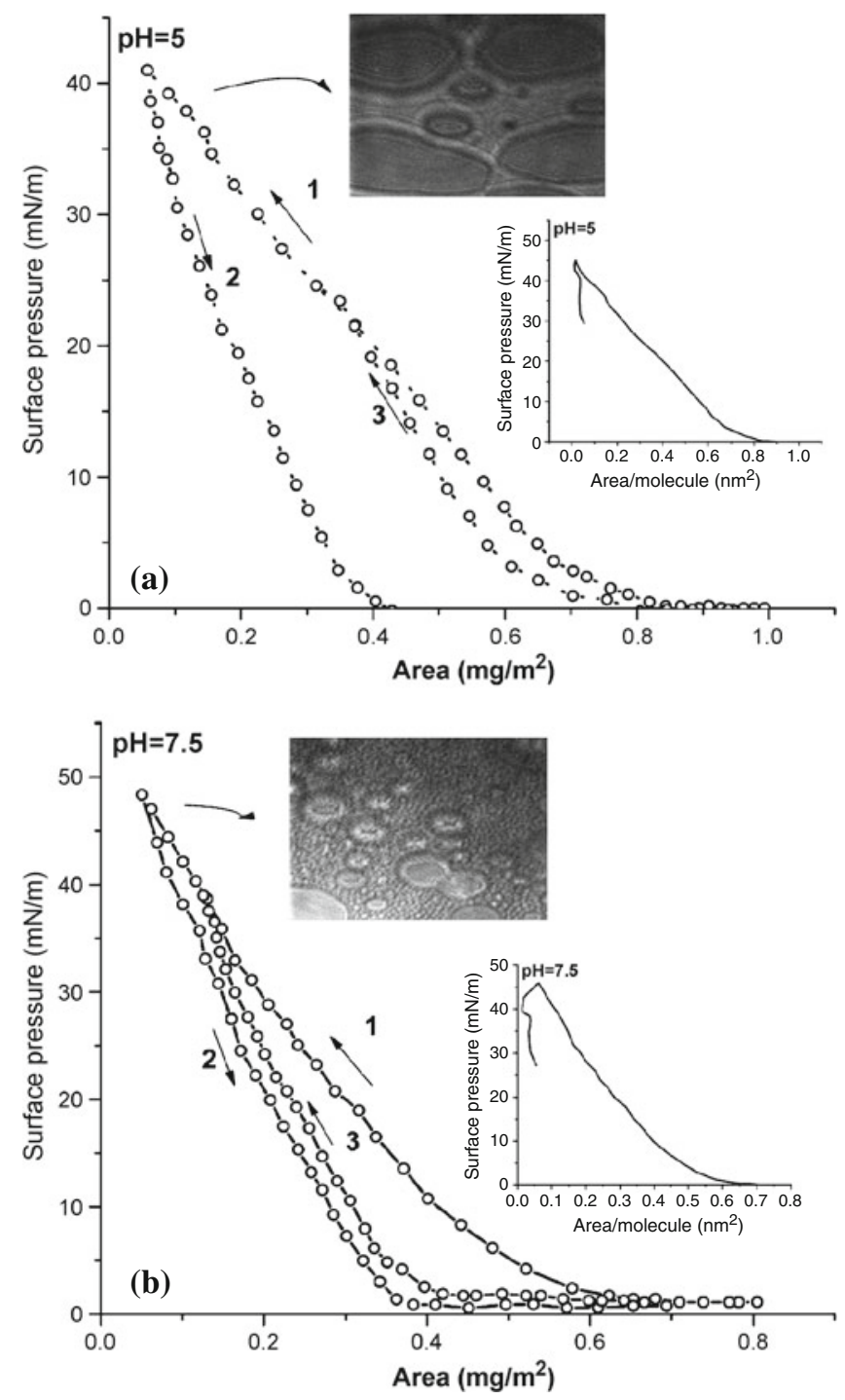

Figure 2. Surface pressure-area isotherms of Langmuir films of capsules at (a) $\mathrm{pH}=5.5$ and (b) $\mathrm{pH}=7.5$ (inset Brewster angle micrographs scale bar: $70 \mu)$. sizes are formed. At this $\mathrm{pH}$ which is closer to the isoelectric point of $\mathrm{Hb}(\mathrm{pI}=6.8)$, precipitation of the protein could be initiated. Since the temperature is low the aggregation process overrides the precipitation resulting in multi-layered structures with smaller capsules growing within larger capsules. At both $\mathrm{pH}$ values, the particles sizes range between 0.2 and $0.4 \mu$.

Capsules have been spread as Langmuir films at air/water interface and pushed together using a barrier to form an insoluble film in a Langmuir trough. Figure 2 shows the isotherms of the spread films of the capsules at $\mathrm{pH}=5.5$, and 7.5 spread on buffer of $\mathrm{pH}=6.8(\mathrm{pI}$ of $\mathrm{Hb}$ ).

From the isotherms, the physical state of the protein molecules at the air/water interface can be obtained from the surface pressure $\pi$ (the interfacial tension due to the layer), and $\Gamma$, the adsorbed protein amount per unit area.

The simple model for the film of close packed capsules assumes that for sufficiently dilute solutions the film should obey the 2D ideal gas law, and the capsules are like discs packed at the air/water interface. In order to verify whether the discs pack into a monolayer different volumes of the solution was spread and using the same compression rate the isotherms were recorded. For the different volumes spread, nearly the same surface coverage was obtained suggesting that the discs do pack into a monolayer. Assuming Volmer's equation of state $^{23}$

$$
\pi(1 / \Gamma-\alpha)=\mathrm{kT},
$$

which is normally applicable to globular proteins, one can extend it to spherical capsules. Here $\alpha$ is the 'excluded area per particle'; kT is the thermal energy, and the adsorption $\Gamma$ is measured in number of particles per $\mathrm{cm}^{2}$. Thus, the film obeys the equation of state irrespective of the concentration in the bulk, for a complete monolayer (about $0.8 \mathrm{mg} / \mathrm{m}^{2}$ ) coverage. This also suggests that the layer behaves as a collection of non-interacting hard disks.

In general, the observed isotherms for spread films show three distinct regions. At a low bulk concentration, the surface pressure is nearly zero while the adsorption shows values near $1 \mathrm{mg} / \mathrm{m}^{2}$. Thus, although there are adsorbed molecules on the interface, due to the lack of appreciable interactions the surface pressure remains quite low. At every instant as the surface pressure is measured it corresponds to the instantaneous $\Gamma$. Thus, for the duration of the experiment the protein molecules residing on the interface do not undergo any noticeable configurational rearrangement and denaturation. As the area is reduced on compression, the surface 
pressure begins to rise steeply. At high areas the surface pressure rises relatively slowly. The region of rapid rise in pressure prior to collapse is due to the fusion between the capsules on compression. The slight kink seen between 22 and $27 \mathrm{mN} / \mathrm{m}$ in both isotherms seem to be an artifact arising from the compression speed and disappeared with faster compression.

The compression modulus $\mathrm{C}_{\mathrm{s}}^{-1}$ is a parameter used to define the different states of the monolayer ${ }^{24,25}$ and the collapse pressure and is obtained from $\mathrm{C}_{\mathrm{s}}^{-1}=$ $-\mathrm{A}(\partial \pi / \partial \mathrm{A})$.

At the collapse pressure the value approaches zero. Using this criterion, the maximum collapse pressures for the different systems used in the present study have been estimated to be between 40 and $45 \mathrm{mN} / \mathrm{m}$ (as seen in inset in figure 2). Repeated compression and expansion by carrying out experiments before collapse is reached showed that at $\mathrm{pH} 5.5$ the hysteresis is higher due to the repulsion between the charged particles. At $\mathrm{pH}=7.5$, the average area of the capsules in the close packed state is large possibly due to the differently sized capsules which can fuse to make mutilayered capsules. Moreover, this $\mathrm{pH}$ is close to the $\mathrm{pI}$ of the protein and therefore some level of precipitation could be initiated at the interface.

The BAM images of the capsules (in the inset) at the close packed region show that at $\mathrm{pH} 5.5$ the domains are small while at $\mathrm{pH}=7.5$ they form fairly large domains and are of different sizes. The inhomogenity seen in the close packed region may arise from different size distributions partial aggregation due to local charge compensations.

The protein capsules are composed of both hydrophobic and hydrophilic segments in appropriate proportion, and at the air/water interface they exhibit properties of a Janus-type particle with one of the hemispheres hydrophilic and the other hydrophobic. Thus, even if there exist charges on these capsules they still self-assemble into a monolayer. Due to strong stabilizing effect of the lateral electrostatic repulsions, such monolayer can be compressed to form close-packed hexagonal structure, and then easily transferred onto a solid substrate with the Langmuir-Blodgett technique. The assumption in this study is that the particles are preferentially adsorbed at the interface, where they are thought to form a monolayer. However, experimentally it is usually not possible to determine the exact value of the interfacial coverage of a monolayer.

In order to gain insight into the elasticity and stability of the capsules at the interface, the dilational rheology of the films has been measured. The general trends in the dilational rheological parameters for the capsules at $\mathrm{pH}=5.5$ and 7.5 at the air/water interface are presented in figure 3 . While the change in elasticity values as a function of frequency of dilations are similar for both $\mathrm{pH}$, the absolute elasticity values at $\mathrm{pH}=7.5$ are higher compared with that at $\mathrm{pH}$ 5.5. This is due to the reduction in the net protein charge at $\mathrm{pH} 7.5$ (near to $\mathrm{pI}$ ), leading to more close-packed films with higher intermolecular interactions. ${ }^{26}$ The measurements of the dilational rheology combined with hysteresis did not show large changes in the dilational parameters suggesting that the capsules are stable and form elastic films at the interface. Overall, the measured dilatational elasticities agree with reported values of globular proteins.

The AFM of 4 layers of films of these capsules on highly oriented graphite are shown in figure $4 a$ and $b$. The films at $\mathrm{pH} 5.5$ form well-defined particles while at $\mathrm{pH}=7.5$ aggregated structures are seen. The dimensions of the capsules at $\mathrm{pH}=5.5$ lie between 0.15 and $0.17 \mu$ while at $\mathrm{pH} 7.5$ the sizes are slightly smaller around 0.12 to $0.14 \mu$. The films have been transferred at about $35 \mathrm{mN} / \mathrm{m}$ well below the collapse pressure
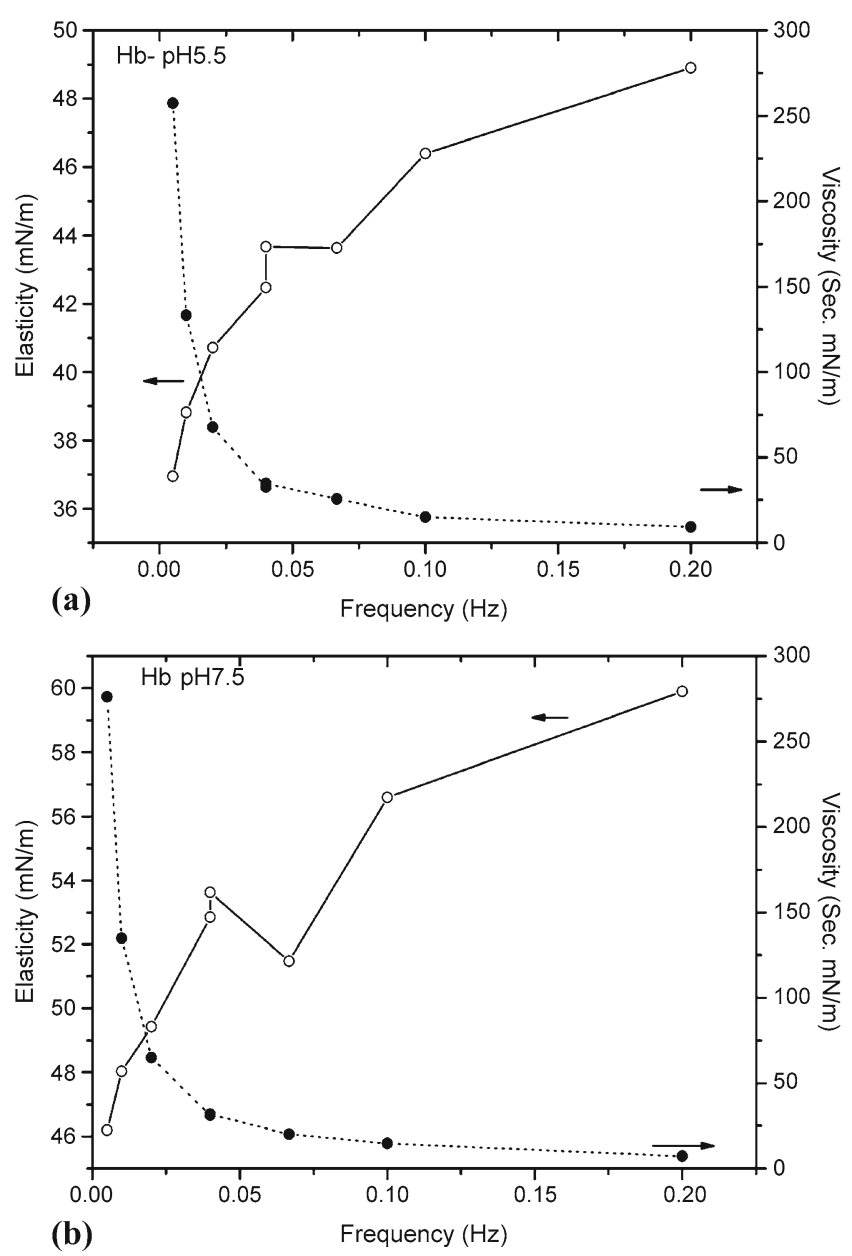

Figure 3. Dilational elasticity and viscosity of the capsules at $(\mathbf{a}) \mathrm{pH}=5.5$ and $(\mathbf{b}) \mathrm{pH}=7.5$. 
(a)

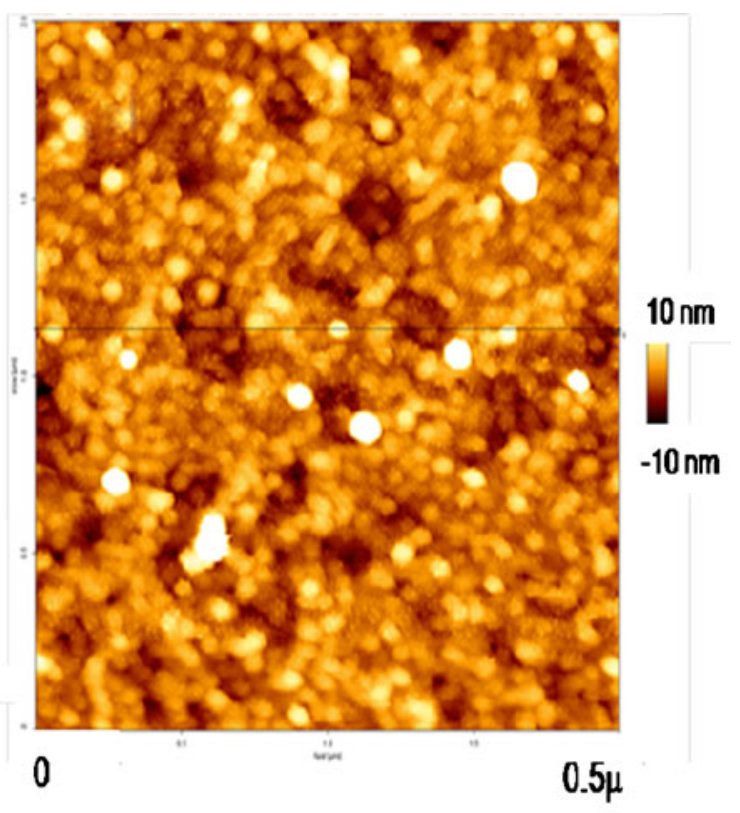

(b)

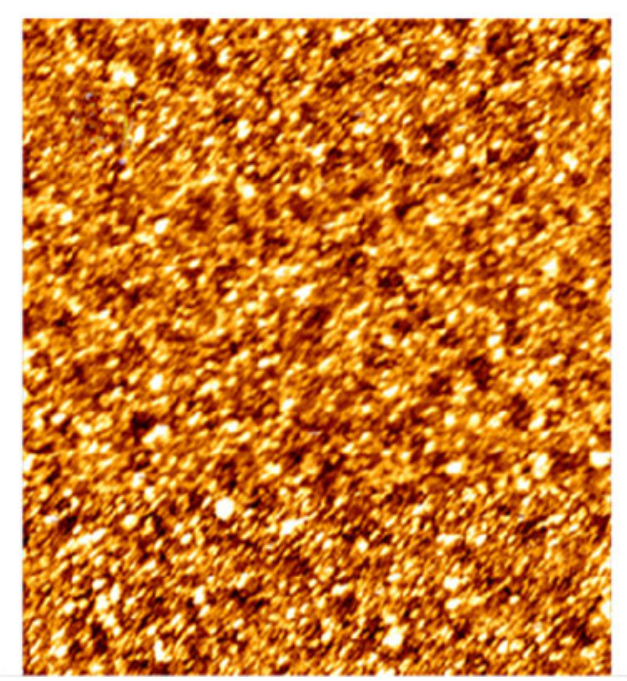

Figure 4. AFM of films transferred to solid substrate (a) $\mathrm{pH}=5.5$ and (b) $\mathrm{pH}=7.5$.

for both $\mathrm{pH}$. Assuming that the capsules show a close packed film, LB film transfer does not seem to alter the packing drastically.

Ideally films transferred at different surface pressures should be analysed for structural features using AFM. However, due to drying, the features are prone to fusion and changes in the morphology. Hence morphology analysis could not be attempted. The stability of the protein in the capsules and as films has been analysed using CD spectroscopy.

Figure 5 shows the representative plots of CD spectra of the capsules in solution (inset) and the films of the capsules transferred to solid substrates for $\mathrm{pH}=5.5$. For the sake of brevity, all the plots at all $\mathrm{pH}$ are not shown here. The CD spectra for the capsules and the

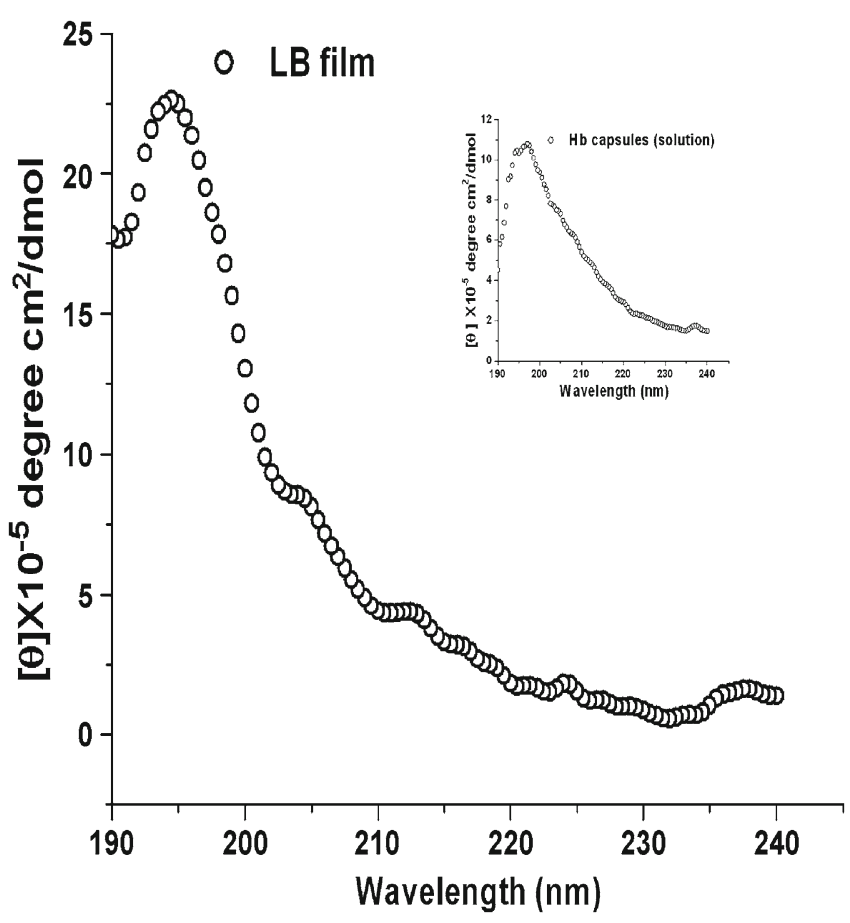

Figure 5. CD spectra of capsules in solution and in films.

LB films suggest that there are no drastic changes in the secondary structural features in both these samples. Deconvolution of the CD spectra showed nearly similar secondary structural features for the capsules at both the $\mathrm{pH}(\mathrm{pH}=5.5$ : helix $\mathrm{r} 74.3 \%$, helix $\mathrm{d} 24.9 \%$ and $0.8 \% \beta$ strand; $\mathrm{pH}=7.5$ : helix r $74.6 \%$, helix d $23.6 \%$, $1.5 \% \beta$ strand, $0.3 \% \beta$ turn) suggesting that the capsule formation did not alter the conformation of the protein.

Adsorption behaviour of the films of the capsules on solid surfaces was studied using QCM.

Using the radius dependent sensitivity of the electrode surface in the QCM and by applying a Gaussian distribution one can define

$$
\mathrm{S}_{(\mathrm{r})}=\mathrm{k} \exp \left[-\beta \mathrm{r}^{2} / \mathrm{r}_{\mathrm{e}}^{2}\right],
$$

where $k$ is the maximum mass sensitivity at $r=0$, $\mathrm{r}_{\mathrm{e}}$ is the radius of the electrode on the QCM, and $\beta$ is the steepness of the Gaussian function. For a droplet of radius $=\mathrm{r}_{\mathrm{d}}$ one can estimate from $\Delta \mathrm{f}$

$$
\mathrm{r}_{\mathrm{d}}^{3}=\left[-\mathrm{r}_{\mathrm{e}}^{2} \ln (1-\Delta \mathrm{f} / \mathrm{c})\right]^{3 / 2}
$$

Knowing the $r_{d}$ value one can evaluate the contact angle and the liquid drop makes use the following eqn.

$r_{d}^{3}=\left\{\left(3 V_{d} / \pi\right)\left(1-\cos ^{2} \theta\right)^{3 / 2}\right\} /\left(2-3 \cos \theta+\cos ^{3} \theta\right)$.

Thus, from QCM measurements, the $\theta$ values for the different samples adsorbing to the gold-coated quartz surfaces were monitored. 
Assuming a constant interfacial tension value $\gamma$ for the different interfaces, a force balance along the solid surface at the three phase contact line of a liquid in contact with the solid surface gives the contact angle of the work of adhesion can be estimated using the eqn.

$$
\mathrm{W}=\gamma(1+\cos \theta) .
$$

The rate of change in the contact angle with time can give an estimate of rate of work of adhesion. In the present study, change in contact angle $\theta$ as a function of time was estimated for the $\mathrm{Hb}$ capsules adsorbing to gold-coated quartz surface. The change in the work of adhesion $\Delta \mathrm{W}$ as a function of time was estimated using eqn. (5). $\Delta \mathrm{W}$ is the difference between $\mathrm{W}$ at any time $\mathrm{t}$ and $\mathrm{W}$ at steady state conditions

$$
\begin{gathered}
\Delta \mathrm{W}=\gamma\left(1+\cos \theta_{\mathrm{t}}\right)-\gamma\left(1+\cos \theta_{\infty}\right) \\
\Delta \mathrm{W}=\gamma\left(\cos \theta_{\mathrm{t}}-\cos \theta_{\infty}\right) .
\end{gathered}
$$

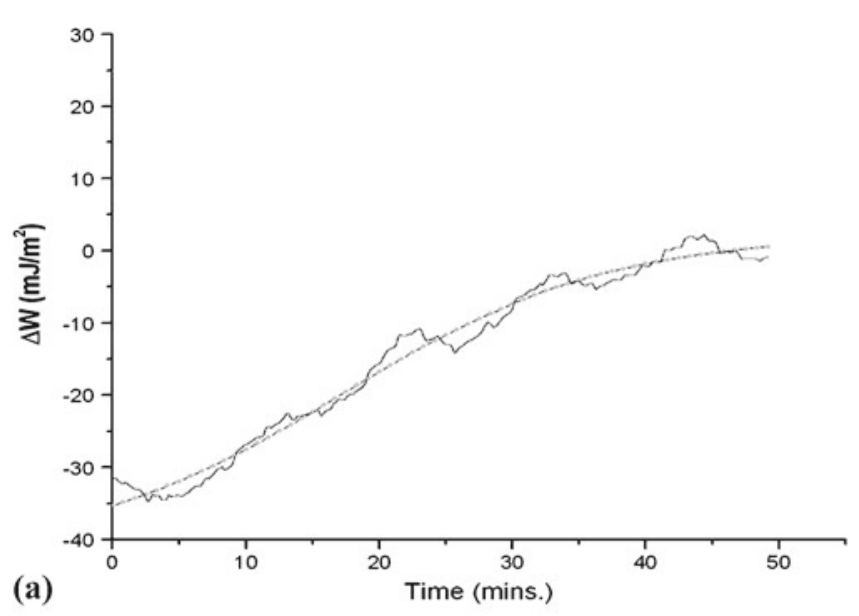

(a)

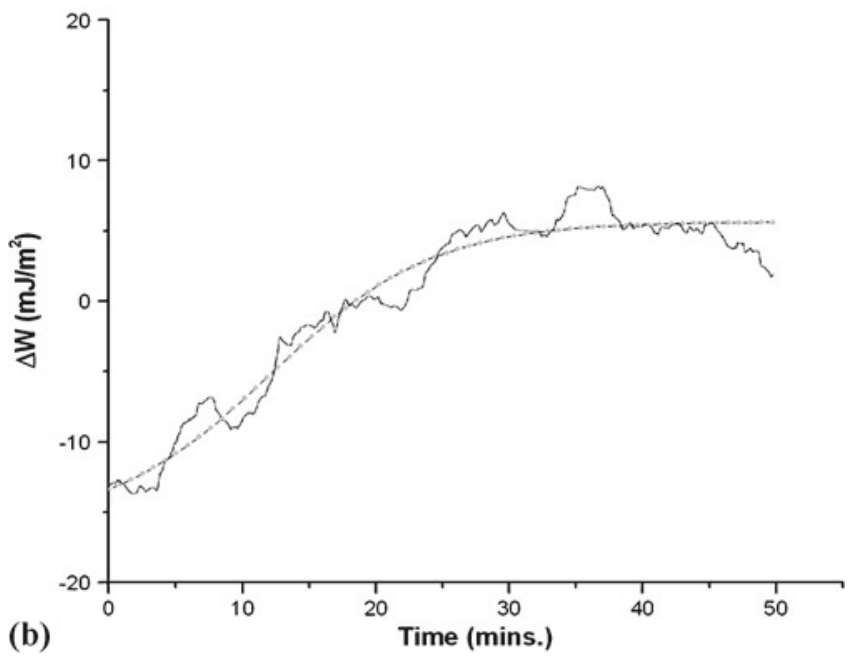

Figure 6. $\Delta \mathrm{W}$ versus time plots for films adsorbing to solid surface (a) $\mathrm{pH}=5.5$, (b) $\mathrm{pH}=7.5$ (based on sigmoidal fit, for $\mathrm{pH}=5.5 \mathrm{~A}_{1}=-41.99, \mathrm{~A}_{2}=2.22, \mathrm{X}_{0}=17.29$ and $\mathrm{dX}=9.97$; for $\mathrm{pH}=7.5 \mathrm{~A}_{1}=-30.7, \mathrm{~A}_{2}=13.29$, $\mathrm{X}_{0}=10.54$ and $\left.\mathrm{dX}=6.54\right)$.
Hence, for $\theta$ values between 0 and 180, based on eqn. (5),

$$
\Delta \mathrm{W}>0 ; \theta_{\infty}>\theta_{\mathrm{t}} ; \text { hindered adsorption }
$$

$\Delta \mathrm{W}<0 ; \theta_{\infty}<\theta_{\mathrm{t}} ;$ promotion of adsorption

$$
\Delta \mathrm{W}=0 ; \theta_{\infty}=\theta_{\mathrm{t}} ; \text { no adsorption. }
$$

The plots of $\Delta \mathrm{W}$ for the $\mathrm{Hb}$ capsules at $\mathrm{pH} 5.5$ and 7.5 adsorbing to the gold coated surface (figure $6 \mathrm{a}$ and b) indicate a negative $\Delta \mathrm{W}$ showing that the adsorption of the capsules is promoted. From the plots, the adsorption of the protein capsules onto the solid surface could be simply represented by two consecutive reactions occurring at the interface as follows

$$
\mathrm{A} \stackrel{\mathrm{k}_{1}}{\longrightarrow} \mathrm{B} \stackrel{\mathrm{k}_{2}}{\longrightarrow} \mathrm{C}
$$

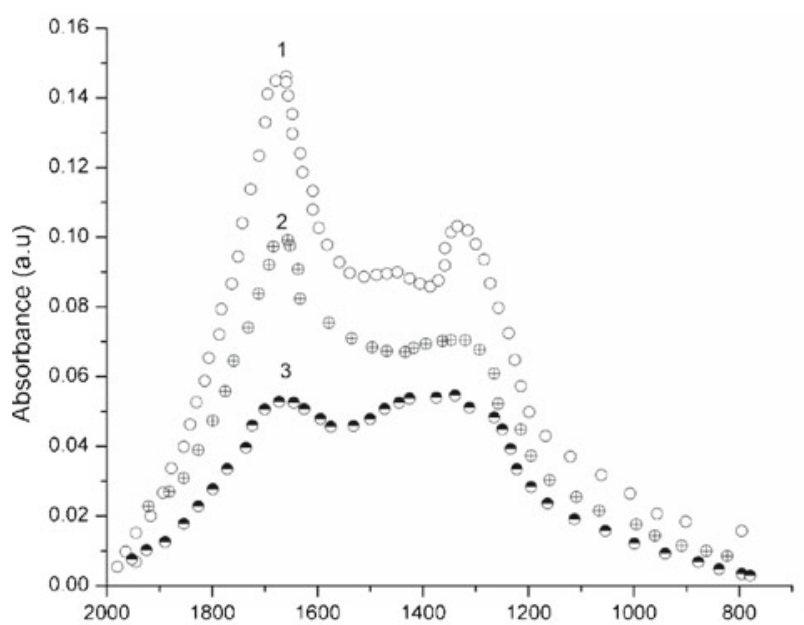

(a)

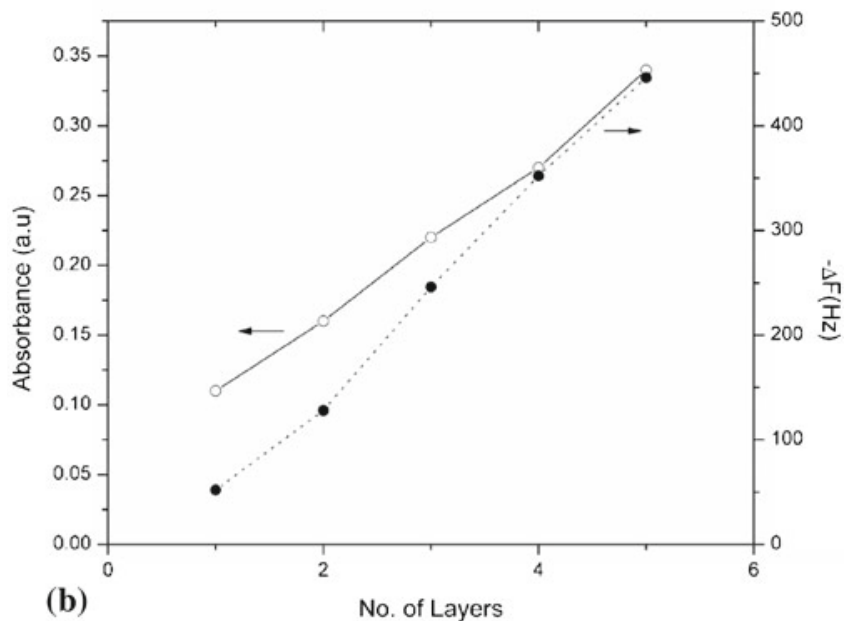

Figure 7. (a) FTIR spectra of amide 1 bands for (1) haemoglobin in solution, (2) as capsules at $\mathrm{pH}=5.5$ and, (3) as capsules at $\mathrm{pH}=7.5$. (b) No. of layers vs UVVis absorbance and $\Delta$ frequency of $\mathrm{Hb}$ capsules at $\mathrm{pH} 5.5$ transferred to solid surface. 
where A represents free protein capsules, B adsorbed protein capsules and $\mathrm{C}$ the rearranged adsorbed protein capsules or the adsorbed capsules in the second adsorption layer.

Both the plots in figure 6 were fitted to a sigmoidal Boltzmann function of the form

$$
\mathrm{Y}=\left[\left(\mathrm{A}_{1}-\mathrm{A}_{2}\right) /\left(1+\exp \left(\mathrm{X}-\mathrm{X}_{0}\right)\right] / \mathrm{dX}+\mathrm{A}_{2}\right. \text {. }
$$

Here, $A_{1}$ and $A_{2}$ denote the initial work of adhesion at $\mathrm{t}=0$, final work of adhesion (steady state), $\mathrm{x}_{0}$ the point of inflexion in the plot and dx the time constant. The fitted values are indicated in the figure legend. The higher $\mathrm{A}_{1}$ value for the capsules at $\mathrm{pH}=5.5$ suggests strong adsorption and supports the multipoint capsule-surface interactions.

The real model of adsorption of the protein capsules is complex and involves many processes such as capsule-interface interactions, protein orientations on the surface, lateral protein-protein interactions, and desorption that lead to multiple states of adsorbed proteins on the surface.

The transferred films were studied using FTIR-RAS. The plots of the amide I $\left(1684-1680 \mathrm{~cm}^{-1}\right)$ and amide III (1400-1390 $\left.\mathrm{cm}^{-1}\right)$ bands are shown in figure $7 \mathrm{a}$ for

(a)

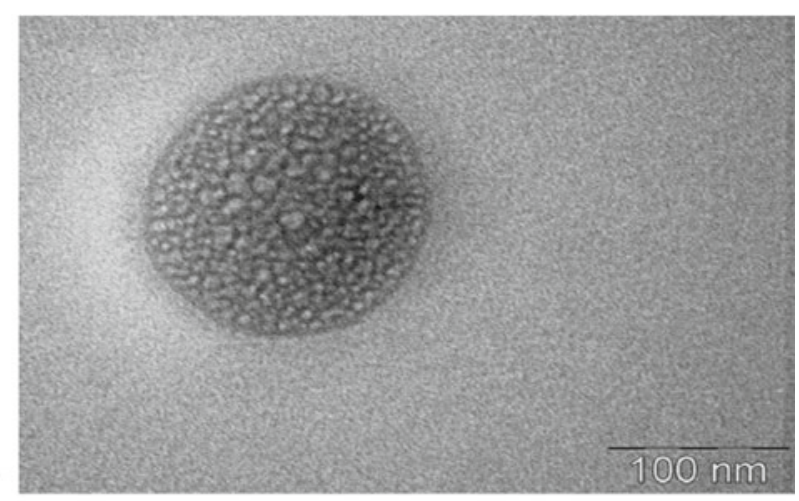

(b)

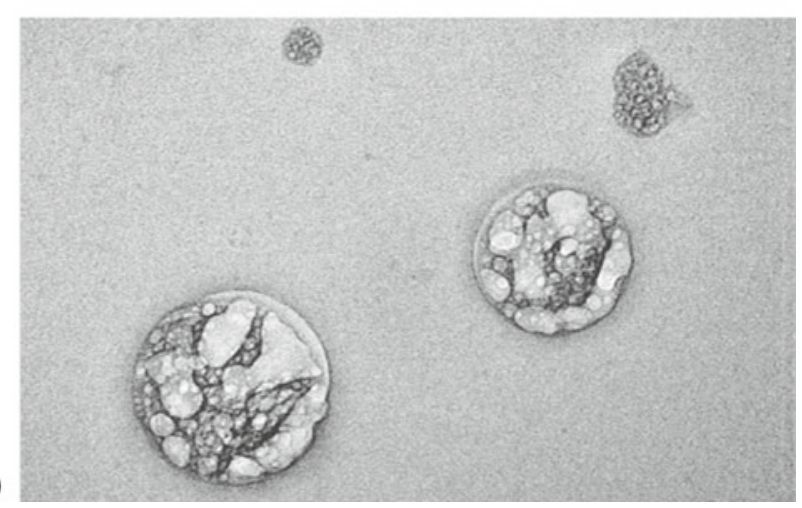

Figure 8. Transmission electron micrographs of capsule at (a) $\mathrm{pH}=5.5$, (b) $\mathrm{pH}=7.5$. haemoglobin solution at $\mathrm{pH}=5.5$, as capsules at $\mathrm{pH}=$ 5.5 and at $\mathrm{pH}=7.5$.

There is a good correlation between the FTIR-RAS and QCM results (figure 7b). An Amide I band centred between $1650 \mathrm{~cm}^{-1}$ and $1665 \mathrm{~cm}^{-1}$ is generally considered to be characteristic of the $\alpha$-helical structures and thus is in agreement with the CD spectral data obtained for the protein capsules.

In general, the FTIR-RAS measurements are sensitive mainly to the vibrational modes that are perpendicular to the substrate, and hence the absorbance could possibly display a dependency on the protein orientation with respect to the number of layers. The absorbance corresponding to amide I band and $\Delta \mathrm{f}$ value (from QCM) for increasing number of layers of the capsule transferred at $\mathrm{pH} 5.5$ showed a strong correlation. The transfer at $\mathrm{pH} 7.5$ did not show this high level of correlation with QCM frequency values suggesting that nearer the $\mathrm{pI}$ the local aggregation precedes
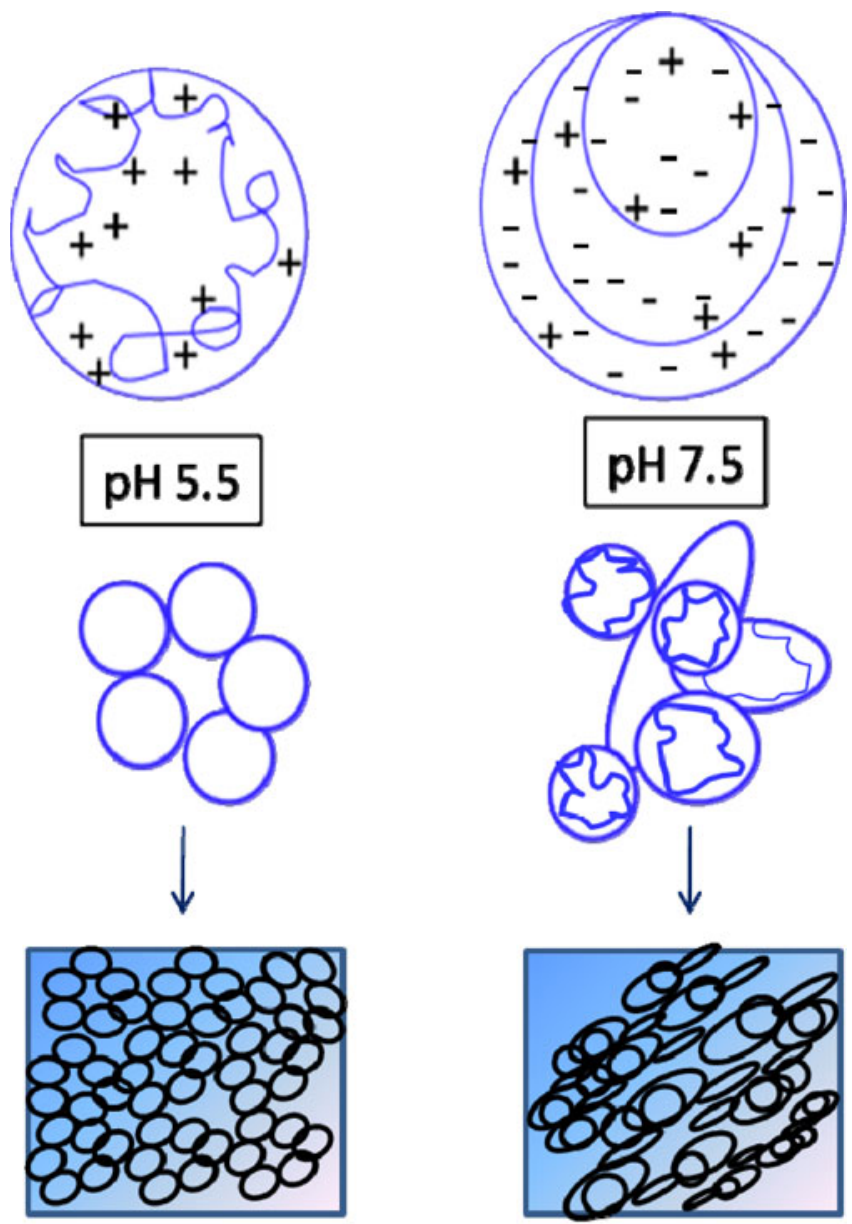

\section{Packing at air/buffer interface}

Figure 9. Scheme of capsule formation at $\mathrm{pH}=5.5$ and 7.5. 
the transfer and hence population of protein molecules perpendicular to the substrates in the capsules may be less.

While adsorption of protein could occur over a time scale of minutes ${ }^{27}$ the kinetic process of changes in secondary structure might be markedly slower, even if changes in polypeptide multilayer structure can occur on a time scale of minutes. At $\mathrm{pH}$ below and above the $\mathrm{pI}$ of $\mathrm{Hb}$, the protein molecules of the same charge will repel each other during the self-regulatory process of adsorption to achieve an organized layer of uniform thickness.

However, as $\mathrm{pH}$ approaches $\mathrm{pI}$, the charge neutralization possibly leads to multilayered capsules. Thus, the lyopilisomes at $\mathrm{pH} 7.5$ appear multilayered. TEM analysis of the films of capsules transferred at the two different $\mathrm{pH}$ (shown in figure 8 shows clearly the formation of the multilayered structure (figure $8 \mathrm{~b}$ ) for the capsules at $\mathrm{pH}=7.5$ ).

In case of rough and not so regular capsules as in the present case, the multilayered capsules possibly are not very compact. It is possible that these multilayered capsules are loosely packed at the air/buffer interface and on compression fuse with neighbouring multilayered structures into less organized assemblies. Thus, the packing of the capsules at different $\mathrm{pH}$ at air/buffer interface determines the formation of different types of organized assemblies as is presented in figure 9.

\section{Conclusion}

In conclusion, this work shows that stable capsules of pure proteins can be designed as films that can find biomedical applications and can be used to encapsulate small peptides and some lipophilic compounds. The study reveals that multilayers of protein capsules can be constructed with regularly ordered protein layers on solid substrates. This study can be extended to fabricate designed capsules of different proteins in thin films and their applications for biosensing devices.

\section{Acknowledgements}

The authors would like to thank the Council of Scientific and Industrial Research (CSIR-NWP0035) (Nanomaterials and nanodevices in health and disease) and DST Nanomission, Govt. of India for project grants. MJ would like to thank the Department of Science and Technology (DST), Govt. of India for the INSPIRE Junior Research Fellowship.

\section{References}

1. Brash J L and Horbett T A 1995 Proteins at interfaces: Fundamentals and applications (Washington: ACS Symposium Series 602) pp. 1-23

2. Dinsmore A D, Hsu M F, Nikolaides M G, Marquez M, Bausch A R and Weitz D A 2002 Science 2981006

3. Lin Y, Skaff H, Emrick T, Dinsmore A D and Russell T P 2003 Science 299226

4. Decher G 1997 Science 2771232

5. Caruso F, Caruso R A and Möhwald H 1998 Science 282 1111

6. Donath E, Sukhorukov G B, Caruso F, Davis S A and Möhwald H 1998 Angew. Chem. Int. Ed. 372202

7. Lvov Y 2000 In Protein architecture: Interfacing molecular assemblies and immobilization biotechnology Electrostatic layer-by-layer assembly of proteins and polyions (eds) Y Lvov and H Möhwald (New York: Marcel Dekker) p. 125

8. Daamen W F, Geutjes P J, van Moerkerk H T B, Nillesen S T M, Wismans R G, Hafmans T, van den Heuvel L P W J, Pistorius A M A, Veerkamp J H, van Hest J C M and van Kuppevelt T H 2007 Adv. Mater. 19673

9. Daisy Vimala Rani J, Kamatchi S and Dhathathreyan A 2010 J. Coll. Interf. Sci. 34148

10. Lu G, An Z and Li J 2004 Biochem. Biophys. Res. Commun. 315224

11. Lu G, Chen H and Li J 2003 Colloid Surf. A215 25

12. Volodkin D V, Larionova N I and Sukhorukov G B 2004 Biomacromolecules 51962

13. Wang Y, Angelatos A S and Caruso F 2008 Chem. Mater. 20848

14. Breguet V, Gugerli R, Pernetti M, von Stockar U and Marison I W 2005 Langmuir 219764

15. Shutava T, Prouty M, Kommireddy D and Lvov Y 2005 Macromolecules $\mathbf{3 8} 2850$

16. Shrivastava H Y, Dhathathreyan A and Nair B U 2003 Chem. Phys. Lett. 369534

17. Lakshmanan M and Dhathathreyan A 2006 J. Coll. Interf. Sci. 30295

18. Dhathathreyan A and Maheshwari R 2002 Langmuir 18 10039

19. Cicuta P and Terentjev E M 2005 Eur Phys. J. E16 147

20. Whitmore L and Wallace B A 2008 Biopolymers 89392

21. Bartels J, Borchers H, Hausen H, Hellwege K H, Schäfer K and Schmidt E 1962 Landolt- Börnstein: Zahlenwerte und Funktionen aus Physik, Chemie, Astronomie, Geophysik und Technik-II Eigenschaften der Materie in ihren Aggregatzuständen (Berlin: Springer)

22. Duan L, He Q, Yan X, Cui Y, Wang K and Li J 2007 Biochem. Biophys. Res. Commun. 354357

23. Israelachvili J N 1992 Intermolecular and surface forces (London: Academic Press)

24. Harkins W D 1954 The physical chemistry of surface films (New York: Reinhold)

25. Davies J T, Rideal E K 1963 Interfacial phenomena, 2nd ed. (New York: Academic Press)

26. Murray B S 2002 Curr. Opin. Coll. Interf. Sci. 7426

27. Jordan C E, Frey B L, Korngruth S and Corn R M 1994 Langmuir 103642 